\title{
Distribution and size fractionation of dissolved cobalt and nickel along the Amazon estuary and mixing plume
}

\section{ADRIENNE PATRICIA HOLLISTER ${ }^{1}$, LEANDRO MACHADO} DE CARVALHO ${ }^{2}$, MARTHA GLEDHILL ${ }^{3}$, ANDREA KOSCHINSKY-FRITSCHE ${ }^{4}$

${ }^{1}$ Jacobs University Bremen gGmbH, Campus Ring 1, 28759 Bremen, Germany, a.hollister@jacobs-university.de

${ }^{2}$ Departamento de Química, Universidade Federal de Santa Maria, Santa Maria, Brazil, lemacarvalho@gmail.com ${ }^{3}$ GEOMAR Helmholtz-Zentrum für Ozeanforschung, Wischhofstraße 1-3, 24148 Kiel, Germany, mgledhill@geomar.de

${ }^{4}$ Jacobs University Bremen gGmbH, Campus Ring 1, 28759

Bremen, Germany, a.koschinsky@jacobs-university.de

The Amazon River has the largest volume output on earth and is an important source of trace metals to the Atlantic Ocean. The GEOTRACES process study cruise GApr11 was conducted in April-May 2018 during a period of high river discharge to examine the mixing and transport processes in the Amazon River estuary and mixing plume. Surface samples were collected along the full salinity gradient $(\mathrm{S}=0$ - >35) in the Amazon and Para River outflow regions, mangrove belt to the south, aging plume north and offshore North Brazil Current. Trace metal samples were filtered for analysis at several size fractions: particulate $(>0.2 \mu \mathrm{m})$, dissolved $(<0.2 \mu \mathrm{m})$, colloidal $(0.015-0.2 \mu \mathrm{m})$, soluble $(<0.015 \mu \mathrm{m})$ and ultrafiltered $(1$ and $10 \mathrm{KDa})$. Here we present size-fractionated data for dissolved cobalt $(\mathrm{Co})$ and nickel $(\mathrm{Ni})$, which serve as important micronutrients and are influenced by organic ligand complexation. Comparative analyses using voltammetry and ICP-MS with SeaFAST preconcentration were conducted and gave similar results. Both Co and Ni generally correlated negatively with salinity, with influences from the Amazon and Para rivers. However, a mid-salinity $(\mathrm{S} \sim 15-20)$ local minimum for both metals indicates possible biological uptake and/or particle adsorption. Increasing concentrations following the minimum may reflect desorption from particles due to increasing chloride complexation. In general, $\mathrm{Co}$ and $\mathrm{Ni}$ were predominantly in the soluble fractions, although elevated colloidal fractions were observed near shore. 